Res Publica Revista de Historia de las Ideas Políticas

ISSN: $1131-558 \mathrm{X}$

\title{
J. E. Valls Boix, Giorgio Agamben: Política sin obra, Colección Pensamiento político posfundacional, Barcelona, Gedisa, 2020, 158 pp.
}

El libro que aquí se reseña aparece ahora en castellano después de su publicación en catalán el año 2018, también por Gedisa. Pertenece a la colección de "Pensamiento político posfundacional", dirigida por la Dra. Laura Llevadot. En dicha colección se han publicado diferentes obras sobre filósofos contemporáneos que plantean su pensamiento acerca de la política desde otro punto de vista, alejándose de la tradición filosófica, y señalando la carencia de fundamentación del poder o de la autoridad en las democracias modernas, o, como diría Derrida, mostrando "el fundamento místico de la autoridad"; cuestionan, en fin, cómo se ha constituido el mundo político que todos damos por sentado. Foucault, Derrida, Rancière, entre otros, son algunos de los autores que se han trabajado en esta colección que intenta acercar la filosofía política actual a un público más amplio, sin dejar de lado el rigor y precisión necesarios para contar con dichas obras como interesante bibliografía secundaria.

No abunda en nuestras librerías bibliografía en torno al pensamiento de Agamben. En Giorgio Agamben: Politica sin obra, Juan Evaristo Valls Boix, de forma excepcionalmente lúcida, transmite el pensamiento de Agamben presentando una introducción a su obra, que no por ser introductoria resulta somera o incompleta. Más allá de ser un libro sobre Agamben es un ejercicio filosófico de comprensión de la obra del autor italiano presentada por la ingeniosa mano de Valls Boix. No es, pues, una mera divulgación del pensamiento del filósofo, sino un acercamiento que se realiza desde un transitar entre lo escrito por Agamben y la lectura perspicaz del autor del libro. No obstante, de las líneas escritas se desprende una claridad que permite al lector no especializado adentrarse en el entresijo de conceptos e ideas que se encuentran en la obra de Agamben. Obra que no resulta fácil de seguir cuando el pensador desglosa la vida política para pensar una política de la vida.

Los temas tratados en el libro son muy diversos; van desde los conceptos de vida nuda, la potencia y la inoperancia hasta el uso del cuerpo, todos ellos atravesados por los conceptos de soberanía, poder y estado de excepción. Así, el ensayo queda repartido en nueve capítulos, precedidos por una introducción de Laura Llevadot. A modo de cierre encontramos una breve biografía de Agamben y su bibliografía.
Para abrazar tan vasto contenido, el autor arranca con una pregunta que será contestada a lo largo de todo el ensayo: “¿Cómo y cuando nuestra vida se vuelve política?". Pasando por Foucault, llega a Agamben:

Si Foucault encontraba en la biopolítica un paradigma arraigado en un momento histórico determinado, Agamben aplicará su diagnóstico a todo ser humano, haciendo de la biopolítica una cuestión ontológica [debido a que] toda la metafísica de Occidente y el ejercicio consecuente de la política han funcionado siempre como una operación del poder sobre la vida (pp. 14-15).

Es en corrección de la tesis foucaultiana, en tanto que el poder siempre se ha impuesto sobre la vida, no solo en un momento concreto, donde encontramos una de las aportaciones más destacadas del pensador italiano y el punto de inicio de su filosofar. La consecuencia más preocupante del modo en que la política entra en la vida es que esta queda escindida en una peligrosa dicotomía: por un lado, la vida que resulta estimable para la política $y$, por otro, la vida que es relegada y excluida, sin espacio político, es decir, la vida nuda. Pero esta vida nuda es "incluida en la exclusión" porque, en tanto que vida que debe ser suprimida, posibilita la aparición de la vida legítimamente política. Queda así patente la vulnerabilidad de la vida nuda en su rol de víctima para posibilitar aquella otra que sí tiene sentido político. En contraposición a esta vida nuda encontramos la soberanía, cuyo poder es infinito y que, paradójicamente, se basa en ella. En palabras de Agamben: "La violencia soberana no se funda, en verdad, sobre un pacto, sino sobre la inclusión exclusiva de la nuda vida en el Estado". El poder del soberano es inseparable de la vida nuda, ambos se fundamentan mutuamente; el poder ilimitado que posee el soberano es inseparable de la vulnerabilidad, también ilimitada, de la vida nuda.

El estado de excepción, noción que Agamben toma de Schmitt, constituye el mecanismo por el cual cualquier vida puede convertirse en vida nuda quedando bajo el mando del soberano. Valls Boix dedica un capítulo al estado de excepción: en él encontramos la afirmación de que "lo que otorga la legitimidad al poder al

G. Agamben, Homo Sacer. El poder soberano y la vida nuda, Valencia, Pre-Textos, 1998, p. 138. 
soberano es una ficción" (p. 26). No existe, pues, una fundamentación esencial o radical del poder; la capacidad de ejercer el poder es lo que legitima al soberano hacer uso del mismo. En este aspecto es donde podemos insertar a Agamben en el pensamiento posfundacional.

Si se tensa esta idea y se lleva a sus últimas consecuencias llegamos al estado de excepción, donde el soberano puede hacer uso legítimo de la violencia, dejando en suspenso la legalidad establecida. Cuando el soberano, máxima expresión de la ley, decide que necesariamente debe implantar el estado de excepción se establece la ilegalidad como forma de proteger la legalidad; es la suspensión de la norma, del orden. Agamben señala como paradigmas de la política contemporánea la guerra civil y los campos de concentración: son representaciones normalizadas del estado de excepción. Es en los campos donde la vida nuda, la desnudez del cuerpo, queda desplazada a mero dato biológico, a mera vida.

Como respuesta Agamben intenta pensar una política fuera de la operatividad, es decir, una política de la vida. Ya desde la tradición filosófica el ser ha sido tomado como operatividad. Un claro exponente de este camino de pensamiento es Aristóteles y su diferenciación entre entelequia o acto y potencia. La potencia debe ser actualizada en actividad. En la modernidad se vierten estas categorías en la ética y la política redefiniendo su significado en un "deber ser" -anteriormente puesto en práctica en los procedimientos litúrgicos-. De ahí que broten los imperativos kantianos que regulan el actuar humano. Así, el actuar, a saber, la operatividad se torna, no un elemento más del ser humano, sino su máxima expresividad.

Tal y como arguye Valls Boix, Agamben retomará el concepto de potencia de modo que podamos "concebir al hombre como un ser que puede, que es eminentemente posibilidad y potencia, pura plasticidad que se ensaya, y ya no un ser que quiere o un se que ha de actuar" (p. 52). La potencia se define por su capacidad de no ponerla en práctica, es decir, de no actualizarla. Sin la potencia perdemos la capacidad de negarnos, de decir no. $\mathrm{Y}$ es precisamente por esta capacidad que Agamben cree conveniente rescatar la potencia que, a su vez, permitirá pensar una política de la potencia y dejar de lado la política del poder.

Dentro de la mencionada política de la potencia, el concepto que el autor rescata de Agamben es el de inoperancia -que no debemos confundir con ociosidad-. Tal concepto proporciona una apertura a la posibilidad sin encajarla en una actividad ya acabada y definida. Se trata de atender la propia potencia en el actuar, de trascender la acción mediante la observación de aquello que subsiste de la potencia en el mismo actuar, ya que siempre queda algo en potencia de ser de otra manera, una posibilidad abierta. Será en la vertiente potencial donde Agamben situará la especificidad del ser humano. Y si lo propio del hombre es la posibilidad, la finalidad exigida en su actuar queda desplazada a un lado para dar paso a lo que Agamben se refiere como gestos que escapan de la lógica medio-fin. Dichos gestos no responden a ninguna finalidad ni orden y por ello la vida, entendida como una acumulación de gestos, se desenvuelve como un juego que huye de la relación binaria medio-fin.

Es la política el campo del gesto, donde existen solo los medios y no hay lugar para los fines. La política es "un espacio de medios sin fin, de medios puros que dibujan otras oportunidades para la vida y para el pensamiento" (p. 86).

Después de examinar el uso del cuerpo como trabajo principal de la política de los medios puros, Valls Boix nos lleva hasta el capítulo titulado "Forma-de-vida" en el que queda de manifiesto el intento de Agamben por pensar una política que tenga en cuenta la forma de la vida. Es decir, una nueva política que no lleve indefectiblemente a la escisión entre vida legítima y vida nuda, repensando la actividad y contemplando la vida como pura potencia; se ha dejado atrás el actuar y se reclama el ser y el vivir. Se trata de llevar a la vida fuera del derecho: "Se llama forma-de-vida, pues, a esa vida que celebra la autarquía y resulta, por ello, inabarcable por el derecho" (p. 112), lo cual permite, al fin, que el poder no pueda ejercerse de la manera en que lo hace en las formas políticas actuales y, por lo tanto, que la dicotomía vida legítima-vida nuda quede fuera del ámbito político, amparándose ambas en una conjunción inseparable. La forma-de-vida, así, queda alejada de los dispositivos de poder y se eleva a un estado casi ingobernable.

En conclusión, Valls Boix ofrece esta introducción a Agamben a partir de muchos elementos que harán que el lector pueda entender mejor a qué tipo de problemáticas se está intentado dar salida. Solícitamente el autor de este libro nos lleva de la mano por las entrañas del pensamiento de Agamben, argumentando cada paso -que aquí tan solo se han podido apuntar-, utilizando diferentes estrategias para iluminar al lector en su camino: las referencias literarias son constantes, pero es en el último capítulo donde el autor acerca la filosofía de Agamben al medio audiovisual, en su interpretación sobre la mítica serie Twin Peaks, para re-presentar lo analizado a lo largo del ensayo. Si a ello le sumamos la capacidad de Valls Boix para transmitir lo irrenunciable en la obra de Agamben en tan solo 158 páginas, tenemos como resultado un libro fuera de lo común y preciso para explicitar lo que subyace, es decir, el fondo último que se desprende del pensamiento de Agamben: pensar una política sin obra.

Natalia Rodríguez Inda 